\title{
A tortura no estado atual: uma breve reflexão da sua origem e suas consequências na produção da subjetividade
}

\author{
Cristiane Ferreira Fraga*
}

Este artigo se propõe a problematizar as produções subjetivas no contexto da população em situação de vulnerabilidade social. O Estado que previamente deveria assegurar a integridade física do indivíduo, muitas vezes age de maneira oficiosa com ações violentas e danosas ao corpo e a mente. As Políticas de Segurança transformam a vida na favela em um campo bélico. A tortura tem longa história nas civilizações, marcando corpos e produzindo memória.

Palavras-chave: Violência, Produção de Subjetividade, Estado.

This article aims to discuss the subjective productions in the context of the population in situation of social vulnerability. The State should ensure that advance the physical integrity of the individual, often acts in a way unofficially with violent actions and harmful to the body and mind. Security Policies transform life in the slum quarter a constant field of warlike. However, torture has a long history in civilization, marking bodies and producing memory

Key words: Violence, Production of Subjectivity, State
A modernidade exige cidades limpas, assépticas, onde a miséria - já que não pode ser mais escondida e/ou administrada - deve ser eliminada. Eliminação não pela sua superação, mas pelo extermínio daqueles que a expõe incomodando os "olhos, ouvidos e narizes" das classes mais abastadas.

(Cecília Coimbra)

$\mathrm{N}$ ão é difícil perceber a ação policial nas favelas do Rio de Janeiro. Todos os dias em nossos telejornais somos contemplados com reportagens que descrevem as estratégias policiais em combate ao crime organizado e ao tráfico de drogas. De acordo com dados oficiais do Instituto de Segurança Pública do Rio (ISP), a polícia matou nos chamados "autos de resistência" 1.137 pessoas em 2008 .

\footnotetext{
* Mestranda do Programa de Pós Graduação em Psicologia da Universidade Federal Fluminense. Instituto de Ciências Humanas e Filosofia. E-mail: crisfragapsi@hotmail.com
} 
No ano de 2009 existe uma média de três mortos por dia. O ISP indica o aumento das mortes nos últimos anos durante a chamada "política de enfrentamento" do atual governo estadual.

Justificando sua visita ao Brasil em Novembro de 2009, a comissária de Direitos Humanos da Organização das Nações Unidas (ONU), a sul-africana Navanethem Pillay, afirma: “[...] me disseram que há até um genocídio de negros no país, o que é motivo de grande preocupação e razão da minha visita".

As populações do Rio de Janeiro em situação de vulnerabilidade social, na grande maioria negros, têm enfrentado a cada dia a luta pela vida. De um lado, uma política de segurança pública que tem como lema o extermínio de uma classe considerada perigosa - e por isso perfeitamente matável -, do outro a classe média atravessada pela mídia, não cessa de pedir por punições, e a acaba por favorecer que se pratique essa política oficiosa de extermínio.

Violência e assassinato não são práticas recentes do Estado Brasileiro. Sem que seja preciso um grande esforço da memória poderemos lembrar de um período em que a tortura era a principal especialidade do Estado. Durante o período da Ditadura Militar no Brasil, opositores ao governo foram presos, torturados e mortos.

Temos ainda hoje com resultado desta época em que os militares precisavam proteger o Brasil contra os pensamentos subversivos da esquerda um total de 137 pessoas desaparecidas ${ }^{1}$. Os não simpatizantes do Governo Militar eram presos e torturados, muitos não resistiam e acabavam morrendo, no entanto em alguns casos seus corpos nunca foram encontrados, suas famílias foram impedidas de sepultá-los.

Em 9 de dezembro de 1975, período da ditadura militar, que começou com o Golpe 1964 e só terminou em 1985, foi aprovado na Assembléia Geral das Nações Unidas a Declaração sobre a Proteção de Todas as Pessoas Contra a Tortura e Outras Penas ou Tratamentos Cruéis, Desumanos ou Degradantes².

\footnotetext{
${ }^{1}$ Informação contida no site do Grupo Tortura Nunca Mais/ Rio de Janeiro. Disponível em: http:// www.torturanunca mais-rj.org.br/ acessado em 15.5.2010.

${ }^{2}$ Biblioteca virtual dos direitos humanos. Declaração sobre a proteção de todas as pessoas - 1975. São Paulo. http://citrus..uspnet.usp.br/dh/index..phd/ Acessado em 15.05.2010.
} 
Em 1984 a ONU na Convenção contra a tortura e outros tratamentos ou penas cruéis desumanos ou degradantes, considerando a carta assembléia de 1975, o reconhecimento dos direitos iguais e inalienáveis de todos os membros da família humana, a obrigação do Estado de promover o respeito universal e a observância dos direitos humanos e das liberdades fundamentais e levando em conta o "artigo 5" da Declaração Universal dos Direitos do Homem e o "artigo $7^{0}$ " do Pacto Internacional sobre Direitos Civis e Políticos, que determinam que ninguém será sujeito a tortura ou a pena ou tratamento cruel, desumano ou degradante, define a tortura:

[...] o termo "tortura" designa qualquer ato pelo qual dores ou sofrimentos agudos, físicos ou mentais, são infligidos intencionalmente a uma pessoa a fim de obter, dela ou de terceira pessoa, informações ou confissões; de castigá-la por ato que ela ou terceira pessoa tenha cometido ou seja suspeita de ter cometido; de intimidar ou coagir esta pessoa ou outras pessoas; ou por qualquer motivo baseado em discriminação de qualquer natureza; quando tais dores ou sofrimentos são infligidos por um funcionário público ou outra pessoa no exercício de funções públicas, ou por sua instigação, ou com o seu consentimento ou aquiescência. Não se considerará como tortura as dores ou sofrimentos que sejam consequência unicamente de sanções legítimas, ou que sejam inerentes a tais sanções ou delas decorram. ${ }^{3}$

A Convenção contra a tortura e outros tratamentos ou penas cruéis desumanos ou degradantes, foi adotada pela resolução n. 39/46 da Assembléia Geral das Nações Unidas em 10 de dezembro de 1984 e ratificada pelo Brasil em 28 de setembro de 1989.

Percebemos que as práticas de tortura não fazem apenas parte do nosso passado, tampouco são simplesmente uma demanda existente no presente, por conta do crime organizado. Os torturados mudaram, agora não é mais o inimigo político que pode ter seu direito transgredido, mas o morador da favela, aquele que ameaça a paz da classe média. Culpado ou suspeito, não importa, o que vale é que mais um vez o Estado, aquele quem deveria assegurar o direito à vida, mata, tortura e viola os direitos humanos.

\footnotetext{
${ }^{3}$ Parte I, artigo $1^{\circ}$, ONU.
} 


\section{Origem da tortura}

O Ministério Público de São Paulo denunciou [...] quatro policiais militares acusados de espancar e matar o motoboy Alexandre Menezes dos Santos, de 25 anos, na madrugada do dia 8 de maio. [...] Segundo o MP, o jovem apanhou por entre 20 a 30 minutos. Os policiais agiram "impelidos por absoluto desprezo pela vida do jovem pardo, pobre, periférico, desprezando os pedidos da mãe da vítima para que parassem as agressões e ameaçando-a de prisão se interviesse". [...] Alexandre Santos foi morto quando chegava em casa [...] após trabalhar como entregador em uma pizzaria. Segundo informações do Boletim de Ocorrência (BO), um dos policiais aplicou uma gravata no motoboy na tentativa de imobilizá-lo, mas ele teria conseguido se desvencilhar. Então, outro golpe foi dado. Alexandre perdeu os sentidos e desmaiou, morrendo pouco tempo depois. [...] Em entrevista ao iG, a mãe de Alexandre, [...] disse que implorava para [os policiais] pararem de bater em seu filho. "Eu me ajoelhei, tentei pegar na mão deles (policiais) e implorava para pararem de bater no meu filho. Eles só diziam: 'fica quieta que você pode ser presa' [...] Quando perguntei o motivo da agressão ao meu filho, o policial apenas respondeu: 'estava cumprindo o meu trabalho'. O trabalho deles era matar o meu filho". ${ }^{4}$

Essa história nos parece assustadora, no entanto não é com dificuldade que encontramos manchetes parecidas em nossos jornais. A cada dia a violência policial faz novas vítimas. Cada história com suas particularidades, no entanto segue a questão: Para que tanta violência?

Primo Levi contando sua experiência nos campos de concentração, fala sobre a violência útil, aquela que tem como objetivo a morte do inimigo, a morte por dinheiro, para se vingar de uma ofensa ou até as mortes nas guerras. ${ }^{5}$ Esse tipo de violência visa um objetivo, muitas vezes iníquo ou perverso, mas não é gratuita, não se propõe infligir sofrimentos, apesar dele existir. Já a violência inútil, tem fim nela mesma, voltada unicamente para a criação da dor.

Como pensar em um objetivo útil quando se imagina a cena de quatro policiais armados espancando um único jovem? Com qual objetivo quatro homens

\footnotetext{
4 "MP denuncia quatro policiais por morte de motoboy". Jornal Último Segundo Brasil. São Paulo, acessado em 17/05/2010. http://ultimosegundo.ig.com.br

${ }^{5}$ LEVI, Primo. (org.) Os afogados e os sobreviventes. RJ: Paz e Terra, 1990.
} 
armados batem em um homem desarmado? Como achar uma justificativa para tanta violência inútil?

Na busca por uma resposta e percorrendo a filosofia, a psicologia e a antropologia podermos ter algumas análises sobre a origem da tortura e a história do castigo, e como em diferentes épocas e povos, tais práticas tinham diferentes significados e objetivos.

Em uma reflexão genealógica da moral Friedrich Nietzsche descreve como durante um grande período da história, o castigo não era para que o culpado fosse responsabilizado por seu ato delinqüente, mas sim pela idéia de que qualquer dano poderia ser compensado com a dor do seu causador: idéia de equivalência dano e dor. ${ }^{6}$ Essa equivalência dano e dor teve origem na relação contratual credor e devedor. Onde o devedor para transmitir confiança e seriedade em sua promessa, empenha ao credor algo que ainda "possua", como o corpo da sua mulher, sua liberdade ou mesmo a sua vida. O pagamento em dinheiro, terra ou algum bem pode então ser substituído por uma alguma satisfação íntima concedida ao credor, satisfação de quem pode livremente usar seu poder sobre um impotente. Através da punição o credor goza da sensação de poder desprezar e maltratar alguém como inferior. A compensação pelo dano é um convite e um direito à crueldade.

Através da relação devedor-credor, nasce o sentimento de culpa, o homem devendo honrar com sua dívida. Para isso é preciso que ele lembre que está devendo, então é necessário à memória para que o homem seja responsável, confiável e capaz de fazer promessas. Sacrifícios, penhores e martírios, muito sangue acompanhou a necessidade de o homem criar em si uma memória. Quanto mais fraca a memória da humanidade, mais duras serão as leis penais e maior o esforço para vencer o esquecimento e manter as determinações do convívio social. Com uma breve apreciação em nossas antigas legislações penais compreenderemos quanta dor precisou para se criar pensadores. A razão, a seriedade o domínio sobre os afetos, todas essas coisas fundamentais para a vida na sociedade tiveram um alto preço pago pelo homem, tudo a custo de muito horror. ${ }^{7}$

${ }^{6}$ NIETZCHE, Friedrich. Genealogia da moral: Uma polêmica. SP: Companhia das Letras, 2004. ${ }^{7}$ Idem. 
A partir da relação devedor-credor, viver em comunidade significa desfrutar de proteção, paz e confiança, esses são os deleites de uma vida em comunidade. Mas caso o indivíduo não cumpra com seu compromisso, o credor traído exigirá pagamento. O criminoso é um devedor a ira do credor irá devolvê-lo ao estado selvagem e fora da lei que até então ele era protegido.

O 'castigo' nesse nível de costumes, é simplesmente a cópia, mimus [reprodução] do comportamento normal perante o inimigo odiado, desarmado, prostrado, que perdeu não só o direito e proteção, mas também qualquer esperança de graça, ou seja, é o direito de guerra e a celebração do Vae victis! [Ai dos vencidos!] em toda a sua dureza e crueldade - o que explica por que a própria guerra (incluindo o sacrifício ritual guerreiro) forneceu todas as formas sob as quais o castigo aparece na história. ${ }^{8}$

Teremos na história outras razões para tortura que não a descrita por Nietzsche, onde a idéia de causar dor tinha o objetivo de compensar o dano sofrido pelo credor. Pierre Clastres, ao pesquisar a tortura nas sociedades primitivas, a descobre com uma forma de marcar o corpo do jovem para que assim ele faça uma inserção na vida adulta da tribo. Os "ritos de passagem" são de fundamental importância para a tribo, o corpo é o único local propício para conter o sinal do tempo, o traço de uma passagem. O corpo mediatiza a aquisição de um saber, esse saber é inscrito no corpo. O objetivo da iniciação em seu momento de tortura é marcar o corpo, a sociedade imprimi sua marca no corpo dos jovens. A marca proclama com segurança seu pertencimento ao grupo. ${ }^{9}$

Assim como em Nietzsche, é necessário lembrar, a tortura marca tanto o corpo do jovem que precisa recordar da sua responsabilidade com a tribo, quanto daquele que deve e precisa lembrar-se de honrar com sua dívida. A memória é feita através da dor, uma marca física para que a mente não esqueça.

A idéia de dívida proposta por Nietzsche volta a aparecer nas tribos primitivas analisadas por Clastres, se comprometer com a tribo como adulto é lembrar-se de sua responsabilidade social com os demais membros.

O homem novamente tem o corpo marcado para que seja capaz de fazer promessas e honrar com seus compromissos, os acordos sociais não podem ser

\section{${ }^{8}$ Idem, p. 61.}

${ }^{9}$ CLASTRES, Pierre. A sociedade contra o estado: pesquisas de antropologia política. Rio de Janeiro: Francisco Alves, 1978. 
quebrados, e agora em um outro momento da história, a ira do povo e a vingança do rei recairá sobre aquele que não lembrou do contrato social. A dor que evoca a lembrança será o retrato da relação condenado - soberano. Os rituais irão continuar a marcar a memória, a lembrança será escrita no corpo do condenado.

Michel Foucault inicia o livro Vigiar e Punir com a aterrorizante descrição de um suplício. ${ }^{10} \mathrm{O}$ condenado, em um grande espetáculo, tinha seu corpo supliciado, esquartejado, amputado, marcado, exposto vivo ou morto em praça pública. O sofrimento físico e a dor do corpo faziam parte da pena.

O suplício não é apenas a privação do viver, mas uma técnica para produzir certa quantidade calculada de tortura para reter a vida no sofrimento. Para esse cálculo era levada em consideração a gravidade do crime cometido, a pessoa do criminoso e o nível social de suas vítimas, assim era determinado o tipo e a intensidade de ferimentos e o tempo de sofrimento e em quanto tempo se deveria deixar o criminoso morrer. O suplício era um ritual, um elemento da liturgia punitiva. Esse ritual tem que ser marcante, ele traça sobre o corpo do condenado sinais que não devem se apagar da memória dos homens, os gritos com excesso de violência fazem parte do cerimonial de justiça que assim manifesta sua força. O suplício se prolongava após a morte do condenado, os cadáveres eram arrastados, expostos, queimados. Uma justiça além do possível sofrimento.

O suplício penal não corresponde a qualquer punição corporal: é uma produção diferenciada de sofrimentos, um ritual organizado para a marcação das vítimas e a manifestação do poder que pune: não é absolutamente a exasperação de uma justiça que, esquecendo seus princípios, perdesse todo o controle. Nos excessos dos suplícios, se investe toda a economia de poder. ${ }^{11}$

Os ritos punitivos eram efeitos de certa mecânica de poder, de um poder que faz valer as regras e as obrigações, a desobediência é um ato de hostilidade, uma ofensa que precisa de vingança.

Rituais de tortura se estenderam até o final do século XVIII e começo do XIX, quando as festas de punição foram sendo substituídas pela nova forma de punir: a privação de liberdade como forma correta de um criminoso pagar por

\footnotetext{
${ }^{10}$ FOUCAULT, Michel. Vigiar e punir: História da violência nas prisões. Petrópolis: Vozes, 2007 ${ }^{11}$ Idem, p. 32.
} 
seu crime. Os protestos contra os suplícios apareciam em toda parte. As cerimônias de punição passaram a ter um cunho negativo, era preciso acabar com a confrontação física entre o condenado e o soberano que era influenciada pela vingança do príncipe e a cólera do povo. A humanização das penas fez com que o carrasco passasse a se parecer com o criminoso, os juízes com os assassinos, o supliciado um objeto de piedade e admiração, a execução pública é agora a chamada de violência.

A pena não era constituída de sofrimento físico, agora o castigo opera sobre o corpo de maneira diferente, um sistema de privação, de obrigação e de interdições sobrevém sobre o corpo.

Apesar da modificação da legislação penal e das diversas discussões sobre os direitos humanos, práticas oficiosas de tortura assombram nosso sistema penal. Suspeitos, detentos, indiciados, a população em situação de vulnerabilidade social são frequentemente vítimas das práticas de tortura em nosso Estado que a muito abandonou o poder soberano por penas mais "dignas" de privação.

Abordagens policiais violentas, caveirão invadindo a favela, inquéritos acompanhados de tortura, todas essas práticas continuam sendo usuais. Qual memória precisa o Estado fazer com as marcas no corpo de suas vítimas? O que agora é necessário lembrar? A busca pela confissão de um crime acompanha muitas ações violentas da polícia, mas para Françoise Sironi a tortura não é para fazer falar, e sim para fazer calar, pois a tortura remete ao silêncio. ${ }^{12}$ Através da tortura uma linha de demarcação surge entre carrascos e vítimas, o torturado é atingido por um sentimento de não pertencimento à espécie humana. Produz-se uma ruptura com seu grupo, essa ruptura poderá ser de modo provisório ou definitivo. O que para os primitivos é um ritual de inserção é agora tido como uma forma de exclusão.

É preciso lembrar quem tem direitos garantidos, é preciso lembrar que o direito à vida não é privilégio de todos, o respeito do Estado e a cidadania não entram na favela; é necessário demarcar espaços para que os pobres não se atrevam a invadir e perturbar a ordem. Quanto maior o sentimento de exclusão provocado pela tortura, mais profunda será a marca da tortura em seus corpos e mentes.

${ }^{12}$ SIRONI, Françoise. Bourreaux et Victimes. Psycologie de La Torture. Paris: Editions Odile Jacob, 1999. 


\section{Processos de subjetivação}

Iremos discutir quais produções subjetivas emergem em uma população que diariamente enfrenta a as ações de "combate à violência" do Estado, onde para que essa ação se faça valer é necessário que muitos sejam torturados e até assassinados.

Proponho usar a palavra "subjetividades" no plural, pois se trata sempre de processos de produção de subjetividades, processos que emergem das relações, logo não podem ser permanentes, mas sim em constantes modificações. Para F. Guattari e S. Rolnik, produção que deriva do entrecruzamento de determinações coletivas de várias espécies, não só familiar, mas também econômica, tecnológica, de mídia entre outras. A subjetividade é fabricada e modelada no registro social a partir de seus diversos atravessamentos. ${ }^{13}$

Pensando assim, a construção do sujeito não é previamente determinada, tampouco uma questão de escolha, mas um agenciamento com o fora, com as forças que perpassam um contexto sócio-histórico em que esse sujeito está inserido. O individual é produzido no coletivo, as diversas relações sociais - familiares, de trabalho, comunitárias, religiosas, dentre tantas outras -, estão todo o tempo nos invadindo e produzindo formas de sentir, pensar e agir. Levando em consideração que a subjetividade familiar também é produzida no social, pensamos que não é possível que a família seja a única responsável pelos processos de subjetivação, mas que essa produção é principalmente um atravessamento social muito mais complexo.

As sociedades modernas ocidentais entendem o homem como uma entidade natural, singular e distinta, como portadora de um "eu", uma essência. A partir dessa noção de eu, funciona grande parte de nossos sistemas penais, com uma idéia de responsabilidade e intenção ${ }^{14}$. A idéia de um indivíduo livre onde suas produções subjetivas são apenas uma questão de escolha faz com que todo o contexto social seja desconsiderado, sem implicações com o mundo ao redor. O sujeito torna-se o único responsável pelo que lhe acontece e pelo que produz.

\footnotetext{
${ }^{13}$ GUATTARI, F.; ROLNIK, S. Micropolitica: cartografias do desejo. Petrópolis: Vozes, 1988.

${ }^{14}$ ROSE, N. “Como se deve fazer a história do eu?” Educação \& Realidade, v. 1, n. 1 (fev. 1976). Porto Alegre: Universidade Federal do Rio Grande do Sul, Faculdade de Educação, 1976, p. 35.
} 
Considerando essa definição de um indivíduo livre das engrenagens sociais, e portador de um "eu” que se constitui distante das implicações sócio econômicas, o capitalismo que mantém grande parcela da população em estado de miséria torna-se isento das produções subjetivas.

A partir de uma "crise do eu" as ciências sociais assistem a morte do sujeito. Assim, rejeita-se a definição de um sujeito universal, estável, totalizado, interiorizado e individualizado. Emerge uma subjetividade socialmente construída, o psicológico não sendo mais uma questão individual, mas, ao contrário, um evento social. Diversas vertentes das ciências sociais compreendem então o subjetivo a partir da análise do que fica de fora do espaço interior; outras vertentes colocam ainda em discussão esse dualismo interior-exterior questionando a possibilidade de um interior que fique a margem de certos processos constitutivos que teriam sua origem no exterior, no social. No entanto, em todas as análises nega-se a possibilidade de uma psique isolada do contexto sociocultural, definindo assim os processos de subjetivação como parte do tecido relacional, processos esses que se constituem nos encontros da trama social.

Deleuze e Guattari ${ }^{15}$, por sua vez, buscam uma crítica mais radical para pensar os processos de subjetivação para além dos pré-supostos que a psicologia continua presa. Frente a uma idéia de sujeito essencializado com uma identidade unitária, Deleuze e Guattari propõem formas de pensar a subjetividade a partir da noção de multiplicidade e heterogeneidade. Através de uma genealogia e cartografia da subjetividade ocidental analisam os processos de subjetivação, pois para ele só existem processos, o eu não está enclausurado, tampouco é interior, mas sim um movimento de agenciamento cuja interioridade transborda ininterruptamente em contato como o exterior. ${ }^{16}$

A produção subjetiva é produzida através dos encontros. Na coexistência entre os corpos se produzem turbulências e transformações, muitas vezes irreversíveis. Quando os fluxos e partículas da nossa atual composição se conectam com outros fluxos e partículas, ou seja, com o exterior e seus elementos estrangeiros, a forma atual é desestabilizada, sendo necessário, nessa medida, criar um

\footnotetext{
${ }^{15}$ DELEUZE, G.; GUATTARI, F. O Anti-Édipo. São Paulo: Editora 34, 2010

${ }^{16}$ DOMENECH, M., TIRADO, F., GOMES, L. “A dobra: psicologia da subjetivação”. In: SILVA, T. (Org.) Nunca fomos humanos - nos rastros do sujeito. Belo Horizonte: Autêntica, 2001, p. 115.
} 
novo corpo afetivo e cognitivo. Novas subjetividades são produzidas a partir destes encontros. ${ }^{17}$

Parece claro, e não há motivo de contestação: a interioridade transborda em contato com o exterior, as subjetividades se produzem a partir dos encontros. Mesmo uma pessoa mergulhada no senso comum não discordaria dessa afirmação. Mas que exterior? Que encontros? Pensaremos aqui o encontro com o fora, com aquilo que é exterior à sua forma atual. O fora é habitado por forças, estratificadas ou não. As forças são múltiplas e nem todas as forças estão capturadas pelos estratos históricos. É através do saber que as relações de força são codificadas, estratificadas. O saber controla e gerencia as relações de poder, tornando as forças plúmbeas a organizadas. ${ }^{18} \mathrm{O}$ poder são as forças, as forças do fora, relações de forças puramente intensivas que, embora cegas e mudas, são a condição para o exercício do saber, isto é, do que podemos ver e falar.

É por meio da visibilidade e dos enunciados, o saber, que ocorre a estratificação das relações de força, o Poder. Dependendo das maneiras pelas quais os corpos estão dispostos na arquitetura, nas instituições, nos agenciamentos sociais, ou seja, nos regimes de visibilidade, nos é permitido ou não enxergar certos elementos. A visibilidade ou a luminosidade é o que determina as condições do que podemos ver em certo lugar e em certa época. A outra via de estratificação do poder utilizada pelo saber são os enunciados. Não se pode enunciar qualquer coisa em qualquer período histórico. Poderemos identificar um modo de subjetivação a partir da estratificação das forças pelo saber, que utiliza a visibilidade e os enunciados para criar maneiras de perceber, pensar, agir, ou seja, estar no mundo. ${ }^{19}$

No entanto temos a produção de subjetividade singular, que não é prevista pelo saber estratificado socialmente, produzida pela dobra do fora, quando, frente aos poderes constituídos, uma força toma outra força como ponto de apoio. É a

\footnotetext{
${ }^{17}$ ROLNIK, S. “A sombra da cidade: alteridade, homem da ética e reinvenção da democracia”. In: MAGALHÃES, M.C.R. (Org.). Na Sombra da Cidade. São Paulo: Ed. Escuta, 1995.

${ }^{18}$ COSTA, Márcio. A "embriologia" dos arquivos: o problema da expressão e da narrativa oral a partir de uma perspectiva deleuziana. In: NASSIF, L. E., NUNES, M. T. (Orgs.) Patrimônio cultural, museus, psicologia e educação: diálogos. (Centro de Documentação e Pesquisa Helena Antipoff). Belo Horizonte: Ed. PUC. Minas, 2009, p. 127.
}

${ }^{19}$ COSTA, Márcio. Op. cit., p. 129. 
subjetividade produzida a partir de encontros insuspeitos, e por sua vez, criadora de novos agenciamentos que traçam linhas de fuga, que descodificam os saberes estabelecidos e desterritorializam as estratégias de poder já constituídas - diferente da subjetividade marcada pelos estratos históricos, definida por linhas duras de saber que codificam certas estratégias de poder. Pois, precisamos lembrar que para G. Deleuze o lado de fora, não é um limite fixo, mas uma matéria móvel, animada de movimentos peristálticos, de pregas e de dobras, que constituem um lado de dentro. ${ }^{20}$ Essa constituição se dá na curvatura do lado de fora, profundas dobras que não ressuscitariam a velha interioridade, mas sim constituiriam um novo lado de dentro, um dentro que seria a prega do fora selvagem, nômade, pura potência virtual e não domesticada ainda pelo saber, os estratos históricos.

No entanto, é importante ressaltar que o dobramento desse fora, isto é, das forças ainda não domesticadas pelo social estratificado, só pode ocorrer por meio de "pregas" ou "pinças", que nada mais são do que estratégias ou táticas de subjetivação. Estas nunca são absolutamente novas, mas sempre tomadas do agenciamento social em que se vive, ainda que agenciadas de outro modo. Significa dizer que novos modos de subjetivação emergem tendo como material os saberes e relações de poderes constituídos, mas fazendo outros usos. É uma forma de resistência ao poder, tomar o estabelecido contra o estabelecido. As táticas ou estratégias são justamente formas historicamente circunscritas da força tomar outra como ponto de apoio e dobrar o fora, isto é, as forças ainda não estratificadas, porque ainda não (ou pouco) mobilizadas, produzindo formas ainda não codificadas de subjetividade. São propriamente os processos de subjetivação em exercício concreto.

Descrevemos então, a partir dos teóricos da esquizoanálise, duas formas para a produção subjetiva: uma que é construída através do saber, por exemplo: o Estado deve manter a integridade física do indivíduo. Sabemos isso através de um estrato histórico e frente a esse conhecimento temos uma maneira de pensar e agir. No entanto novas formas de perceber o Estado podem aparecer. Um novo contato com o fora pode romper com o estratificado, quando por exemplo aquele que deveria guardar sua vida, a ameaça. Frente a isso, o indivíduo, buscando sobreviver, busca táticas em seu ambiente social para resistir à violência que lhe

${ }^{20}$ DELEUZE, G. Foucault. São Paulo: Editora Brasiliense, 1988. 
é imposto. Novos elementos surgem, o cenário se reconfigura, os velhos saberes não se sustentam, um encontro insuspeito transforma sua maneira de perceber, pensar, agir, de estar no mundo. A violência produzida pelo Estado rompe com o instituído, muda percepções e afetos, ou seja, produz subjetividade.

Se o ato violento não provoca a morte, contudo, novos modos de vida emergem, já que a vida é sempre produção do novo e de mudanças. A violência produz marcas, traz consigo um caráter de irreversibilidade e de repetição. Após os acontecimentos traumáticos vividos pelos atingidos pela violência do Estado, as recordações aparecem mesmo que se deseje expulsá-las da consciência. No entanto as recordações podem estar a serviço da vida, trazendo novos modos de existir, novas lutas, sempre linhas de produção de novos modos de organização subjetiva. $^{21}$

${ }^{21}$ RAUTER, C. "Notas sobre o tratamento de pessoas atingidas pela violência institucionalizada". In: BENEVIDES, R., PASSOS, E. e RAUTER,C.(Orgs.). Clinica e Politica Subjetividade e Violação dos Direitos Humanos. Rio de Janeiro: IFB T; Corá Editora, 2002. 